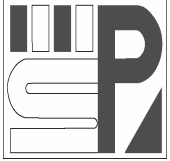

Science Press

Journal of Arid Land

2012, 4(4): 349-356

doi: 10.3724/SP.J.1227.2012.00349

jal.xjegi.com; www.chinasciencejournal.com

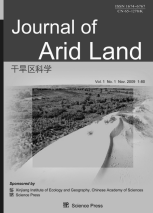

\title{
Effects of cloud, atmospheric water vapor, and dust on photosynthetically active radiation and total solar radiation in a Mongolian grassland
}

\author{
Tserenpurev BAT-OYUN ${ }^{1 *}$, Masato SHINODA ${ }^{2}$, Mitsuru TSUBO ${ }^{2}$ \\ ${ }^{1}$ Meiji University, Tokyo168-8555, Japan; \\ ${ }^{2}$ Arid Land Research Center, Tottori University, Tottori 680-0001, Japan
}

\begin{abstract}
Photosynthetically active radiation (PAR) is an important input parameter for estimating plant productivity due to its key role in the growth and development of plants. However, a worldwide routine network for systematic PAR measurements is not yet established, and PAR is often calculated as a constant fraction of total solar radiation (SR). Although the ratio of PAR to SR (PAR/SR) has been reported from many places, few studies have been performed for dry regions. The present study was therefore carried out in an arid region of Mongolia to obtain PAR/SR and examine its dependency on sky clearness (the clearness index), water vapor in the atmosphere and aeolian dust. Continuous measurements of PAR and SR were taken every one second using quantum and pyranometer sensors, respectively, and the readings were averaged and recorded at intervals of 30 minutes for a period of 12 months. The lowest monthly mean daily PAR/SR occurred in April (0.420), while the highest ratio was observed in July (0.459). Mean daily PAR/SR during plant growing season (May-August) was estimated to be 0.442 , which could be useful for modeling plant productivity in the study area. The annual mean daily PAR/SR $(0.435)$ was lower than the values reported in many previous studies. This difference could be explained with the regional variation in climate: i.e. drier climatic condition in the study area. PAR/SR was negatively correlated with the clearness index $(r=-0.36, P<0.001)$, but positively with atmospheric water vapor pressure $(r=0.47, P<0.001)$. The average PAR/SR was significantly lower $(P=0.02)$ on the dusty days compared to the non-dust days. Water vapor in the atmosphere was shown to be the strongest factor in the variation of PAR/SR. This is the first study examining PAR/SR under a semi-arid condition in Mongolia.
\end{abstract}

Keywords: clearness index; dust storm; photosynthetically active radiation; total solar radiation; water vapor pressure

The photosynthetically active radiation (PAR) is the portion of total solar radiation (SR) in the waveband 0.4-0.7 $\mu \mathrm{m}$, which is available for photosynthesis (McCree, 1972; Ross and Sulev, 2000). In general, plants use PAR as an energy source to convert $\mathrm{CO}_{2}$ and water through photosynthesis into organic compounds (typically sugar, called glucose) which are then used to synthesize structural and metabolic energy required for plant growth and development, respiration, as well as stored vegetative products that result in plant biomass (Udo and Aro, 1999; Jacovides et al., 2004). The accurate determination and clear understanding of the PAR component are required for many applications, such as comprehensive studies of radiation climate, remote sensing of vegetation, radiation regimes of plant canopy and photosynthesis, an essential input in models estimating plant productivity, and carbon exchange between ecosystem and atmosphere (Pinker and Laszlo, 1992; Frouin and Pinker, 1995; Jacovides et al., 2004; Wang et al., 2005; Zhu et al., 2010). A global routine network for measuring PAR is not yet established; however SR is often measured at meteorological stations (Gueymard, 1989; Ross and Sulev, 2000). Due to the limitation of PAR data, this

Received 2012-01-30; accepted 2012-05-11

*Corresponding author: Tserenpurev BAT-OYUN (E-mail: nuyo792000@yahoo.com) 
parameter is often calculated indirectly based on its relationship with SR. Thus, by using such relationship, we could obtain PAR from the existing measured SR (Frouin and Pinker, 1995).

Various empirical relationships between PAR and SR have been derived when both PAR and SR measurements are available. Moon (1940) computed the spectral distribution of direct sunlight for sea level and suggested that PAR/SR was between $44 \%$ and $45 \%$ at places of low altitudes when the sun was more than $30^{\circ}$ above the horizon, while Monteith (1973) suggested that the PAR can be taken as half of the total $\mathrm{SR}$ in the tropics as well as in temperate latitudes based on his measurement at Sutton Bonington $\left(52^{\circ} \mathrm{N}\right.$, $\left.50^{\circ} \mathrm{W}\right)$. However, the use of constant ratio of PAR to $\mathrm{SR}$ (PAR/SR) for different regions could lead to errors in the calculations of PAR (McCree, 1966, 1972; Pinker and Laszlo, 1992). As determined by McCree (1966), the average PAR/SR is 0.48 , with the highest values occurring under cloud-covered sky. Also, other studies have found that PAR/SR was not constant, but varied according to location (Tsubo and Walker, 2005), season (Udo and Aro, 1999; Finch et al., 2004), sky conditions (Rao, 1984; Papaioannou et al., 1993), sky clearness, sky brightness, and atmospheric depth for the solar beam (Jacovides et al., 2004), relative sunshine duration and water vapor pressure (Li et al., 2010), altitude (Wang et al., 2007), irradiance intensity (Britton and Dodd, 1976), day length (Szeicz, 1974; Britton and Dodd, 1976), dust and aerosol (Miskolczi et al., 1997) and pyrogenic aerosols from biomass burning (Finch et al., 2004). This spread of PAR/SR reported in the literature suggested that the relationship between PAR and SR needs to be calibrated according to local climatic conditions.

The atmospheric transmittance includes the attenuation of solar radiation by dust and aerosol scattering, and absorption by water, ozone and other atmospheric gases (Monteith and Unsworth, 1990; Jacovides et al., 2005). Previous studies revealed that atmospheric parameters such as water vapor and cloud cover have the greatest influence on the PAR/SR, followed by dust and aerosol effects (Alados et al., 1996), whereas ozone amount and ground albedo play a minor role in the variation of PAR/SR (Gonzalez and
Calbo, 2002). The ratio increases as sky condition changes from clear to overcast and with the increase of water vapor (Jacovides et al., 2003). Also, dust is considered to be one of the major types of tropospheric aerosols, and constitutes an important parameter affecting visibility, perturbing the radiation energy balance of the earth-atmosphere system, and causing biological and ecological effects (Falkowski et al., 1998; Kaufman et al., 2002; Badarinath et al., 2007; Maher et $a l ., 2010)$. An increase in dust concentration results in increased amount of solar energy absorbed, whereas smaller dust particles are more effective in scattering solar energy than larger particles (Waggoner et al., 1981; Liao and Seinfeld, 1998).

$\mathrm{PAR} / \mathrm{SR}$ has been reported from many places all over the world; however, few studies have been performed over dry regions (e.g. Al-Shooshan, 1997). The aim of this study is, therefore, to determine PAR/SR in an arid region, examine the temporal variations of $\mathrm{PAR} / \mathrm{SR}$, and investigate its dependence on sky conditions, atmospheric water vapor conditions, and dust storm.

\section{Methods}

\subsection{Study area}

The study area is located at Bayan Unjuul $\left(47^{\circ} 02^{\prime} 37.2^{\prime \prime} \mathrm{N}\right.$, $\left.105^{\circ} 57^{\prime} 04.9^{\prime \prime} \mathrm{E}\right)$ in the dry steppe zone of Mongolia (Shinoda et al., 2010). The area is characterized by a semi-arid climate, defined on the basis of aridity index (UNEP, 1992), ranging between 0.2 and 0.5. It is a high altitude $(1,200 \mathrm{~m}$ asl) site with good air transparency, strong solar radiation, and sparse vegetation cover. Summer season has long daylengths and sunshine duration, while winter has short daylengths but mostly clear days due to high pressure system. The natural aerosols increase in spring, with relation to dust storms. The vegetation of Bayan Unjuul is codominated by perennial grasses, forbs, and small shrubs (Shinoda et al., 2010). Generally, the growing season for the Mongolian grasslands is very short (May-August) and it is limited by low temperature and precipitation (Shinoda et al., 2007). The long-term (1995-2008) average air temperature and precipitation over the site are $16.9^{\circ} \mathrm{C}$ and $119 \mathrm{~mm}$, respectively during the growing season. 


\subsection{Data collection}

PAR and total SR $(0.3-3.0 \mu \mathrm{m}$ in wavelength) were recorded from July 2004 to June 2005 with a quantum sensor (LI190SZ, LI-COR Inc., Lincoln, Nebraska, USA) and a pyranometer sensor of the CNR1 net-radiometer (Kipp \& Zonen B.V., Holland) mounted at 1.5 $\mathrm{m}$ height. Data were recorded every one second and the readings were averaged every 30 minutes in a data logger (Campbell Scientific, USA; CR10X). Prior to the measurement, the radiation sensors were calibrated.

\subsection{Calculations}

PAR was expressed in quantum flux $\left(\mu \mathrm{mol} /\left(\mathrm{m}^{2} \cdot \mathrm{s}\right)\right)$, whereas SR was expressed in energy flux $\left(\mathrm{W} / \mathrm{m}^{2}\right)$. Therefore, for comparison PAR photon flux was converted into its energy flux using the constant conversion factor of $0.2195(\mathrm{~W} \mathrm{~s} / \mu \mathrm{mol})$ for a clear sky (Ross and Sulev, 2000).

Daily PAR/SR was calculated by dividing the daily sum of 30-min PAR with daily sum of 30-min SR. These daily values were then averaged over each month and season to get a mean monthly and seasonal daily PAR/SR.

The clearness index (the ratio of total SR to extraterrestrial SR) was used to characterize the sky conditions. In order to investigate the effect of sky conditions on PAR/SR in more detail, we divided the clearness index $\left(K_{T}\right)$ into three equal classes $\left(K_{T}<0.33\right.$ for cloudy days; $0.33 \leq K_{T} \leq 0.67$ for partly cloudy days, and $K_{T}>0.67$ for clear or nearly clear days). Daily extraterrestrial SR $\left(\mathrm{MJ} /\left(\mathrm{m}^{2} \cdot\right.\right.$ day $\left.)\right)$ on a horizontal surface was estimated from the solar constant $(0.082$ $\left.\mathrm{MJ} /\left(\mathrm{m}^{2} \cdot \mathrm{min}\right)\right)$, the solar declination, and hours of solar radiation (Allen et al., 1998).

Three-hourly water vapor pressure data and visual observations of dust storms were obtained from a meteorological station (450 m southeast of the observation site) operated by the Mongolian Institute of Meteorology and Hydrology. At the meteorological station, an observer recorded the duration and intensity of dust storms. In order to reveal the effect of dust storm, we examined the variations of SR, PAR, and PAR/SR between dust days (between sunrise and sunset hours) and non-dust days during the period from April to May in 2005, which is the most frequent dust storm period in Mongolia (Natsagdorj et al., 2003; Jugder et al., 2004). Here, a dust day was indicated as the day in which surface visibility is reduced to below $2,000 \mathrm{~m}$ by strong dust-raising wind. To compare daily radiation between dust and non-dust days, we excluded the cloudy days to avoid cloud effect. Also, it was noted that dust days were evenly distributed in April and May, thus dust and non-dust days didn't cause geometrical effect such as daylength and solar zenith angles.

\section{Results and discussion}

\subsection{Monthly variations of extraterrestrial and to- tal SR and PAR}

Figure 1 shows the monthly extraterrestrial and total SR and PAR at the study area from July 2004 to June 2005. The radiation parameters show similar seasonal variations, with relative peaks in July $(1,250 \mathrm{MJ} /$ $\left(\mathrm{m}^{2} \cdot\right.$ month) of extraterrestrial SR, $734 \mathrm{MJ} /\left(\mathrm{m}^{2} \cdot\right.$ month $)$ of total SR, and $336 \mathrm{MJ} /\left(\mathrm{m}^{2} \cdot \mathrm{month}\right)$ of PAR $)$ and the lowest values in December (293, 177, and $74 \mathrm{MJ} /$ $\left(\mathrm{m}^{2} \cdot\right.$ month), respectively). In comparison, monthly PAR was slightly lower in Ugtaal, Mongolia $\left(48^{\circ} 27^{\prime} \mathrm{N}\right.$, $105^{\circ} 04^{\prime} \mathrm{E} ; 1,160 \mathrm{~m}$ asl), where it varied from 69 to 307 $\mathrm{MJ} /\left(\mathrm{m}^{2} \cdot \mathrm{month}\right)$ (Tugjsuren and Takamura, 2001), than in our study area $\left(47^{\circ} 02^{\prime} 37.2^{\prime \prime} \mathrm{N}, 105^{\circ} 57^{\prime} 04.9^{\prime \prime} \mathrm{E} ; 1,200\right.$ $\mathrm{m}$ asl) due to differences in altitude and latitude. In addition, Ugtaal has more precipitation or greater humidity, resulting in relatively low radiation, compared with Bayan Unjuul. High correlations $(r>0.96)$ were found between the daily SR and PAR on the monthly and seasonal basis, thus allowing the estimation of one component by referring to the other.

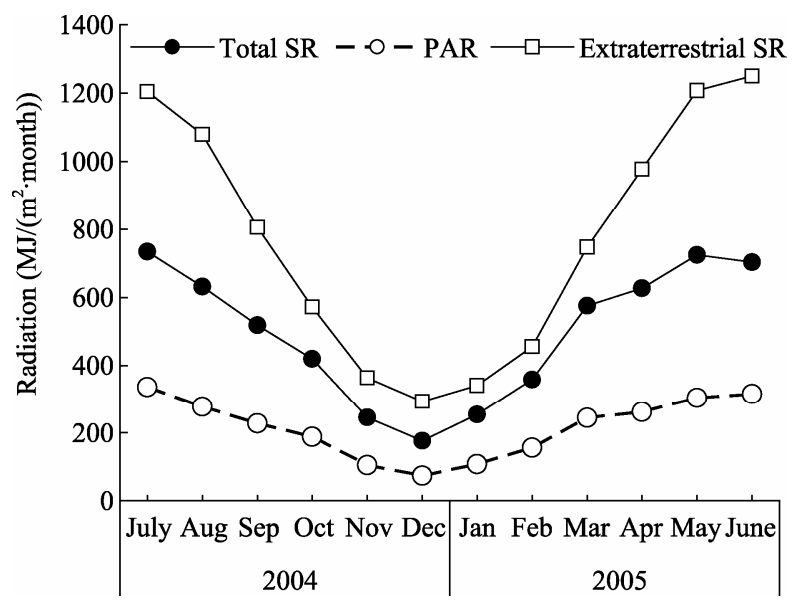

Fig. 1 Monthly extraterrestrial and total SR and total PAR in the study area from July 2004 to June 2005 


\subsection{Diurnal and seasonal changes in PAR/SR}

The diurnal variations of the ratio were examined for each month (Fig. 2). The monthly mean diurnal variations of PAR/SR approached its highest or lowest values (sharp increases or decreases) during either sunrise or sunset hours for most months (January-April, October-December). As the ratio may be affected by lower solar elevation, the data near sunset and sunrise hours should be excluded for hourly-based analysis. The figure further illustrates that during May and September the ratio did not show clear diurnal variations, whereas definite daily patterns are evident from June to August, especially for July, which is the wettest month; the ratio was higher in the morning and
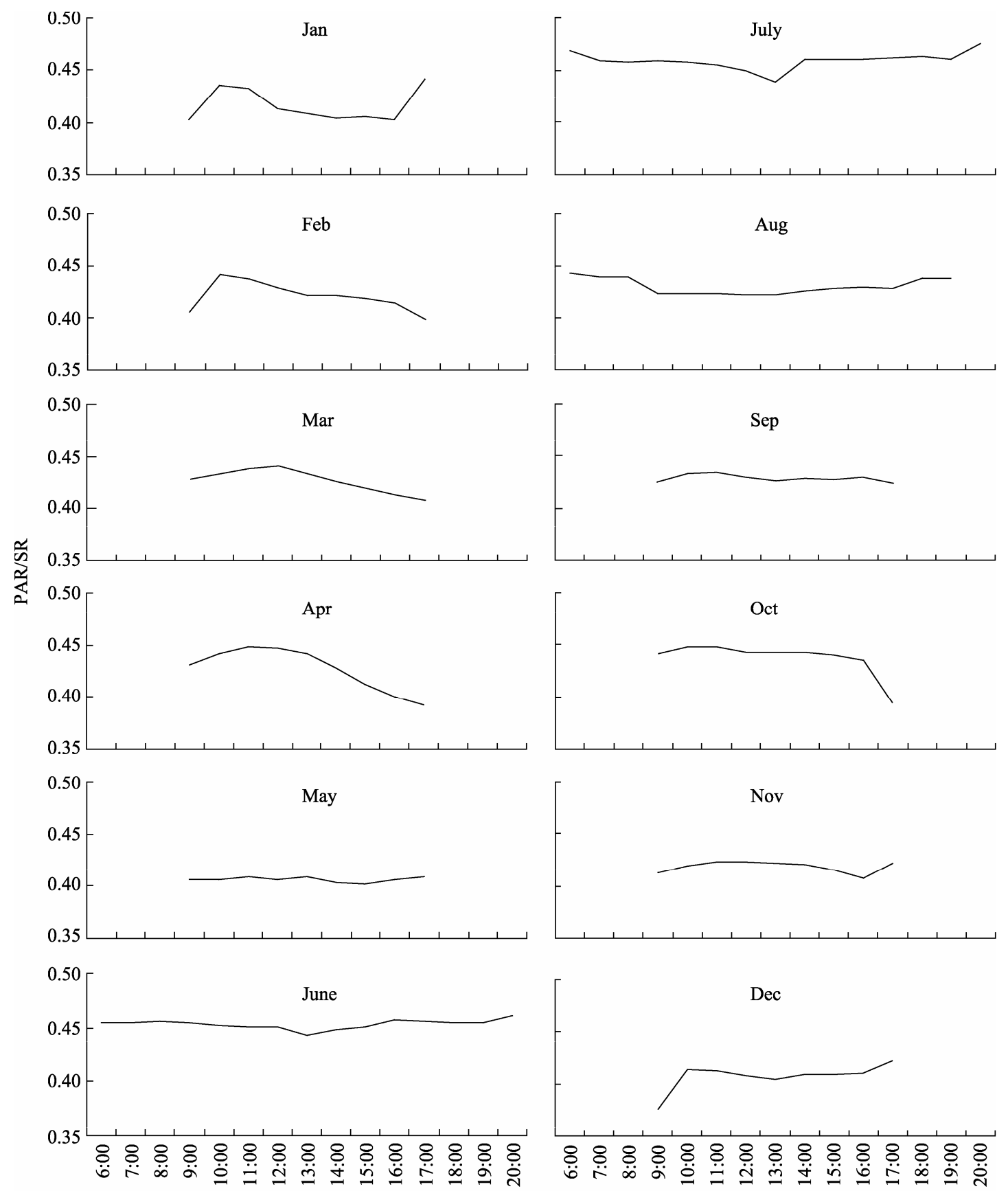

Local time

Fig. 2 Monthly mean diurnal variation of the PAR/SR in the study area 
decreased gradually to its minimum at noon (when the sun is at its highest position in the sky, around 13:00 local time), and then increased in the afternoon. Similarly, in the previous studies PAR/SR reached its highest value during sunset and sunrise, and decreased to the lowest value around noon (13:00 local time in central Nigeria (Udo and Aro, 1999); 12:00-14:00 in Beijing (Hu et al., 2007), and in Naeba Mountain, Japan (Wang et al., 2007)). The similar diurnal variations have presented on the ratio of diffuse to global radiation (a decreasing trend from sunrise to noon and an increasing trend until sunset), as a consequence of enhanced diffuse component in relation to the global radiation at low sun elevation hours whereas the opposite trend occurred around noon (Kaskaoutis and Kambezidis, 2009).

Monthly mean of daily PAR/SR ranged from 0.420 in April to 0.459 in July, with the growing season average of $0.442 \pm 0.021$ and annual mean value of $0.435 \pm 0.019$ (Table 1). The annual mean of daily PAR/SR was lower than those in most previous studies, typically falling between 0.45 and 0.50 , due to the region's dry climatic condition, whereas it was close to the value of 0.43 for Athens, Greece, 0.437 for Sweden, 0.439 for Tibet Plateau (April-October), and 0.440 for Fresno, USA and Aas, Norway. The range of monthly averaged daily PAR/SR $(0.420-0.459)$ was similar to that in Sweden (Rodskjer, 1983), Norway (Hansen, 1984), Greece (Papaioannou et al., 1996), Nigeria (Udo and Aro, 1999) and Tibet (Zhang et al., 2000).

\subsection{Effect of cloud on PAR/SR}

A significant inverse correlation $(r=-0.36, P<0.001)$ was found between the daily PAR/SR and clearness index. However, for very low values of clearness index $(<0.33$, cloudy sky) in the warm-wet season, $\mathrm{PAR} / \mathrm{SR}$ tended to exhibit a more pronounced increase ( $r=-0.71, P<0.001$ ). According to the clearness index, 16 days were considered as cloudy, 141 days as partly cloudy, and 208 days clear or nearly clear (Table 2), indicating that one of the remarkable features of Mongolia is the dominance of clear days. PAR/SR increased from 0.430 on clear days to 0.439 and 0.456 on partly cloudy and cloudy days, respectively. The increases in PAR/SR under cloudy skies were mainly attributable to changes in the absorption spectra of the atmosphere. Clouds absorb more radiation in the infrared waveband than in PAR waveband. An increase in PAR/SR under cloudy conditions has also been reported in previous studies by Papaioannou et al. (1993), Hu et al. (2007), and Tsubo and Walker (2005). However, the effect of the clearness index on PAR/SR was negligible on a daily basis for Fresno, California, USA (Howell et al., 1983).

Table 1 Monthly and seasonal averaged daily PAR/SR, clearness index (Cl), atmospheric water vapor (WVP) and dust days (days of dust storms observed)

\begin{tabular}{|c|c|c|c|c|c|c|c|}
\hline & \multicolumn{2}{|c|}{$\mathrm{PAR} / \mathrm{SR}$} & \multicolumn{2}{|c|}{$\mathrm{CI}$} & \multicolumn{2}{|c|}{ WVP (hPa) } & \multirow{2}{*}{ Dust days } \\
\hline & Average & St. Dev. & Average & St. Dev. & Average & St. Dev. & \\
\hline July & 0.459 & 0.016 & 0.57 & 0.13 & 11.86 & 2.38 & - \\
\hline August & 0.439 & 0.016 & 0.59 & 0.15 & 9.61 & 2.55 & - \\
\hline September & 0.438 & 0.012 & 0.64 & 0.12 & 6.07 & 2.20 & 2 \\
\hline October & 0.449 & 0.012 & 0.73 & 0.09 & 3.28 & 0.97 & 1 \\
\hline November & 0.429 & 0.014 & 0.68 & 0.14 & 1.92 & 0.66 & 1 \\
\hline December & 0.423 & 0.013 & 0.63 & 0.10 & 1.32 & 0.52 & - \\
\hline January & 0.425 & 0.017 & 0.75 & 0.07 & 0.95 & 0.33 & - \\
\hline February & 0.437 & 0.015 & 0.79 & 0.07 & 0.65 & 0.25 & - \\
\hline March & 0.427 & 0.016 & 0.77 & 0.07 & 2.18 & 0.80 & - \\
\hline April & 0.420 & 0.016 & 0.64 & 0.13 & 3.31 & 0.95 & 11 \\
\hline May & 0.421 & 0.010 & 0.64 & 0.11 & 4.68 & 1.47 & 7 \\
\hline June & 0.448 & 0.020 & 0.56 & 0.16 & 8.32 & 1.76 & 2 \\
\hline Growing season (May-Aug) & 0.442 & 0.021 & 0.59 & 0.14 & 8.62 & 3.34 & 9 \\
\hline Annual & 0.435 & 0.019 & 0.66 & 0.14 & 4.54 & 3.83 & 24 \\
\hline
\end{tabular}


Table 2 Number of days with cloudy, partly cloudy and clear sky, averaged PAR/SR with standard deviations for each classification, and correlation coefficient between PAR/SR and clearness index

\begin{tabular}{lcccc}
\hline & \multicolumn{4}{c}{ Clearness index } \\
\cline { 2 - 5 } & $<0.33$ (Cloudy) & $0.33-0.67$ (Partly cloudy) & $>0.67$ (Clear) & $0-1$ \\
\hline Number of days & 16 & 141 & 208 & 365 \\
PAR/SR & $0.456 \pm 0.018$ & $0.439 \pm 0.020$ & $0.430 \pm 0.016$ & $0.434 \pm 0.019$ \\
Correlation coefficient & $-0.71^{*}$ & -0.12 & -0.22 & $-0.36^{*}$ \\
\hline
\end{tabular}

Note: ${ }^{*}$ denotes significant correlations $(P<0.001)$

\subsection{Effect of atmospheric water vapor on PAR/SR}

A significant correlation was found between PAR/SR and water vapor pressure $(r=0.49, P<0.001)$ for day time (08:00-17:00, local time). However, the correlation was stronger during April-September $(r=0.70$, $P<0.001$; Fig. 3a) than in the rest of the study period, i.e. October-March ( $r=0.26, P<0.001 ;$ Fig. 3b). McCree (1966) reported that during cloudy conditions the energy in the PAR region formed a greater part of shortwave radiation than on clear days. Similar seasonal variations in PAR/SR have been reported for Beijing (Hu et al., 2007), where lower PAR/SR was observed during the dry season and higher PAR/SR occurred in the wet season. Thus, in Beijing, PAR/SR is controlled mainly by water vapor in the atmosphere (represented by relative humidity). Similarly, in the study area, it is likely that the increases in PAR/SR were found under cloudy and humid conditions, because the absorption of $\mathrm{SR}$ in the near infrared radiation (NIR) portion of the solar spectrum is greatly enhanced, whereas water vapor is almost transparent to PAR wavelengths. Thus, the decreasing of SR in the NIR range resulted in a higher $\mathrm{PAR} / \mathrm{SR}$ ratio than in the spectral PAR (Alados et al., 1996).

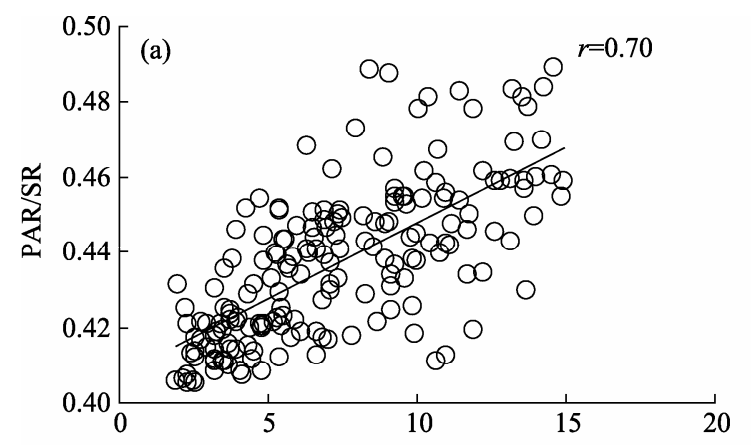

Atmospheric watervapor pressure $(\mathrm{hPa})$

\subsection{Visibility and PAR/SR}

Remarkable decreases in the values of radiation components were found on dust days as compared with non-dust days $\left(20.82 \pm 2.89 \mathrm{MJ} /\left(\mathrm{m}^{2} \cdot\right.\right.$ day $)$ of $\mathrm{SR}$ and $8.53 \pm 1.17 \mathrm{MJ} /\left(\mathrm{m}^{2} \cdot\right.$ day $)$ of PAR on dust days; $22.68 \pm 5.89 \mathrm{MJ} /\left(\mathrm{m}^{2} \cdot\right.$ day $)$ of $\mathrm{SR}$ and $9.5 \pm 2.31$ $\mathrm{MJ} /\left(\mathrm{m}^{2} \cdot\right.$ day $)$ of PAR on non-dust days $)$. Moreover, $\mathrm{PAR} / \mathrm{SR}$ values were significantly lower $(P=0.02)$ during dust days $(0.41 \pm 0.012)$ than on non-dust days $(0.422 \pm 0.016)$ for the dust frequent period in April and May. This effect reflected the fact that the solar radiation in the infrared waveband is more sensitive to the dust aerosol condtion compared with PAR waveband (Jacovides and Karalis, 1996; Jacovides et al., 2003). Diurnal variation of the PAR/SR in March and April revealed marked decreases in the afternoon hours (Fig. 2 ), which may be related with the increases of dust emission during daytime (the highest frequency occurs from 12:00 am to 18:00 pm) when the heating of the ground surface produces wind and unstable conditions in the air (Natsagdorj et al., 2003). Similarly, heavy dust and aerosol loading tended to reduce solar radiation (Mikami, 2007) and PAR/SR in sub-sahel Africa and Cyprus (Miskolczi et al., 1997; Jacovides et al., 2004).

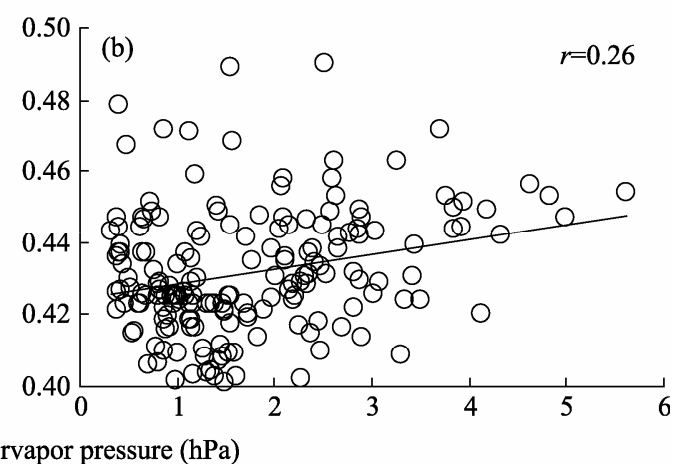

Fig. 3 Relationships between daytime PAR/SR and atmospheric water vapor pressure during the periods of April-September (a) and October-March (b) 
However, Harmattan dust is known to be non-wavelength selective attenuation of total solar radiation in the central Nigeria during winter solstice (Udo and Aro, 1999). A further understanding of the effect of dust aerosols on PAR/SR can be obtained with atmospheric radiation transfer models and satellite retrievals such as MODIS and TOMS Aerosol Index.

\section{Conclusions}

Based on the radiation data recorded at a Mongolian steppe, we analyzed the growing season PAR/SR $(0.442 \pm 0.021)$ and annual PAR/SR $(0.435 \pm 0.019)$ on the daily basis. We investigated the effects of sky condition on PAR/SR, and found that the value of the parameter increased as the clearness index decreased, i.e. sky conditions varied from clear to cloudy. Water vapor in the atmosphere was also found to cause significant changes in PAR/SR. PAR radiation transfers through the atmosphere, and reaches the Earth's surface almost unchanged under a clear sky. On the other

\section{References}

Alados I, Foyo-Moreno I, Alados-Arboledas L. 1996. Photosynthetically active radiation: measurements and modeling. Agricultural and Forest Meteorology, 78: 121-131.

Allen R G, Pereira L S, Raes D, et al. 1998. Crop Evapotranspiration-Guidelines for Computing Crop Water Requirements. Rome, Italy: FAO Irrigation and Drainage Paper, 56: 161-169.

Al-Shooshan A A. 1997. Estimation of photosynthetically active radiation under an arid climate. Journal of Agricultural Engineering Research, 66: 9-13.

Badarinath K V S, Kharol S K, Kaskaoutis D G, et al. 2007. Case study of a dust storm over Hyderabad area, India: its impact on solar radiation using satellite data and ground measurements. Science of the Total Environment, 384: 316-332.

Britton C M, Dodd J D. 1976. Relationships of photosynthetically active radiation and shortwave irradiance. Agricultural Meteorology, 17: $1-7$.

Falkowski P G, Barber R T, Smetacek V. 1998. Biogeochemical controls and feedbacks on ocean primary production. Science, 281: 200-206.

Finch D A, Bailey W G, McArthur L J B, et al. 2004. Photosynthetically active radiation regimes in a southern African savanna environment. Agricultural and Forest Meteorology, 122: 229-238.

Frouin R, Pinker R T. 1995. Estimating photosynthetically active radiation $(\mathrm{PAR})$ at the earth's surface from satellite observations. Remote Sensing of Environment, 51: 98-107.

Gonzalez J A, Calbo J. 2002. Modelled and measured ratio of PAR to hand, NIR is affected greatly by the presence of water vapor in the lower troposphere where water vapor absorbs radiation in this range. These results are in agreement with previous studies and suggest that clearness index and water vapor pressure are the important variables in determining PAR/SR. Solar radiation decreased in dust days due to the scattering and absorption by dust aerosols. The effect of dust storms significantly decreased the PAR/SR. The paper is the first attempt to quantify PAR/SR for a dry region at high latitude; thus our ratio can be used to obtain important parameters of PAR for similar dry regions where SR data are available.

\section{Acknowledgements}

This research was supported by the Global Center of Excellence for Dryland Science Program of the Japanese Society for the Promotion of Science. The authors would like to thank the Institute of Meteorology and Hydrology of Mongolia for providing the required data.

global radiation under cloudless skies. Agricultural and Forest Meteorology, 110: 319-325.

Gueymard C. 1989. A two-band model for the calculation of clear sky solar irradiance, illuminance, and photosynthetically active radiation at the earth's surface. Solar Energy, 43: 253-265.

Hansen V. 1984. Spectral distribution of solar radiation on clear days: a comparison between measurements and model estimates. Journal of Climate and Applied Meteorology, 23: 772-780.

Howell T A, Meek D W, Hatfield J L. 1983. Relationship of photosynthetically active radiation to shortwave radiation in the San Joaquin valley. Agricultural Meteorology, 28: 157-175.

Hu B, Wang Y S, Liu G R. 2007. Measurements and estimations of photosynthetically active radiation in Beijing. Atmospheric Research, 85: 361-371.

Intergovernmental Panel on Climate Change. 2007. Climate change 2007: the physical science basis. In: Solomon S, Qin D, Manning M, et al. Contribution of Working Group I to the Fourth Assessment Report of the Intergovernmental Panel on Climate Change. New York: Cambridge University Press.

Jacovides C P, Karalis J D. 1996. Broad band turbidity parameters and spectral band resolution of solar radiation for the period 1954-1991, in Athens, Greece. International Journal of Climatology, 16: 107-119.

Jacovides C P, Tymvios F S, Asimakopoulos D N, et al. 2003. Global photosynthetically active radiation and its relationship with global solar radiation in the Eastern Mediterranean basin. Theoretical and 
Applied Climatology, 74: 227-233.

Jacovides C P, Tmvios F S, Papaioannou G, et al. 2004. Ratio of PAR to broadband solar radiation measured in Cyprus. Agricultural and Forest Meteorology, 121: 135-140.

Jacovides C P, Kaltsounides N A, Asimakopoulos D N, et al. 2005. Spectral aerosol optical depth and Angstrom parameters in the polluted Athens atmosphere. Theoretical and Applied Climatology, 81: 161-167.

Jugder D, Chung Y S, Batbold A. 2004. Cyclogenesis over the territory of Mongolia during 1999-2002. Journal of the Korean Meteorological Society, 40(3): 293-303.

Kaufman Y J, Tanre D, Boucher O. 2002. A satellite view of aerosols in the climate system. Nature, 419: 215-223.

Li R, Zhao L, Ding Y J, et al. 2010. Monthly ratios of PAR to global solar radiation measured at northern Tibetan Plateau, China. Solar Energy, 84: 964-973.

Liao H, Seinfeld J H. 1998. Radiative forcing by mineral dust aerosols: sensitivity to key variables. Journal of Geophysical Research, 103: 31637-31645.

Maher B A, Prospero J M, Mackie D, et al. 2010. Global connections between aeolian dust, climate and ocean biogeochemistry at the present day and at the last glacial maximum. Earth Science Reviews, 99: 61-97.

McCree K J. 1966. A solarimeter for measuring photosynthetically active radiation. Agricultural Meteorology, 3: 353-366.

McCree K J. 1972. Test of current definitions of photosynthetic active radiation against leaf photosynthesis data. Agricultural Meteorology, 10: 443-453.

Mikami M. 2007. Japan-China collaborative investigation on aeolian dust experiment on climate impact (ADEC). Tenki, 54: 142-150.

Miskolczi F, Aro T O, Iziomon M, et al. 1997. Surface radiative fluxes in sub-sahel Africa. Journal of Applied Meteorology, 36: 521-530.

Monteith J L. 1973. Principles of Environmental Physics. London: Edward Arnold, 23-38.

Monteith J L, Unsworth M. 1990. Principles of Environmental Physics, $2^{\text {nd }}$ ed. London: Edward Arnold, 291.

Moon P. 1940. Proposed standard solar-radiation curves for engineering use. Journal of the Franklin Institute, 230: 583-618.

Natsagdorj L, Jugder D, Chung Y S. 2003. Analysis of dust storms observed in Mongolia during 1937-1999. Atmospheric Environment, 37: 1401-1411.

Papaioannou G, Papanikolaou N, Retalis D. 1993. Relationships of photosynthetically active radiation and shortwave irradiance. Theoretical and Applied Climatology, 48: 23-27.

Papaioannou G, Nikolidakis G, Asimakopoulos D, et al. 1996. Photo- synthetically active radiation in Athens. Agricultural and Forest Meteorology, 81: 287-298.

Pinker R T, Laszlo I. 1992. Global distribution of photosynthetically active radiation as observed from satellites. Journal of Climate, 5: $56-65$.

Rao C R. 1984. Photosynthetically active components of global solar radiation: measurements and model computations. Theoretical and Applied Climatology, 34: 353-364.

Rodskjer N. 1983. Spectral daily insolation at Uppsala, Sweden. Theoretical and Applied Climatology, 33: 89-98.

Ross J, Sulev M. 2000. Sources of errors in measurements of PAR. Agricultural and Forest Meteorology, 100: 103-125.

Shinoda M, Ito S, Nachinshonhor G U, et al. 2007. Phenology of Mongolian grasslands and moisture conditions. Journal of the Meteorological Society of Japan, 85: 359-367.

Shinoda M, Nachinshonhor G U, Nemoto M. 2010. Impact of drought on vegetation dynamics of the Mongolian steppe: a field experiment. Journal of Arid Environments, 74: 63-69.

Szeicz G. 1974. Solar radiation for plant growth. Journal of Applied Ecology, 11: 617-636.

Tsubo M, Walker S. 2005. Relationships between photosynthetically active radiation and clearness index at Bloemfontein, South Africa. Theoretical and Applied Climatology, 80: 17-25.

Tugjsuren N, Takamura T. 2001. Investigation for photosynthetically active radiation regime in the Mongolian Grain Farm Region. Journal of Agricultural Meteorology, 57(4): 201-207.

Udo S O, Aro T O. 1999. Global PAR related to global solar radiation for central Nigeria. Agricultural and Forest Meteorology, 97: $21-31$.

UNEP. 1992. World Atlas of Desertification. London: Edward Arnold.

Waggoner A P, Weiss R E, Ahlquist N C, et al. 1981. Optical characteristics of atmospheric aerosols. Atmospheric Environment, 15: 1891-1909.

Wang Q, Tenhunen J, Schmidt M, et al. 2005. Diffuse PAR irradiance under clear skies in complex alpine terrain. Agricultural and Forest Meteorology, 128: 1-15.

Wang Q, Kakubari Y, Kubota M, et al. 2007. Variation of PAR to global solar radiation ratio along altitude gradient in Naeba Mountain. Theoretical and Applied Climatology, 87: 239-253.

Zhang X Z, Zhang Y G, Zhou Y H. 2000. Measuring and modeling photosynthetically active radiation in Tibet Plateau during April-October. Agricultural and Forest Meteorology, 102: 207-212.

Zhu X D, He H L, Liu M, et al. 2010. Spatio-temporal variation of photosynthetically active radiation in China in recent 50 years. Journal of Geographical Sciences, 20(6): 803-817. 